\title{
BEECH UTILIZATION AND MANAGEMENT PROBLEMS ${ }^{1}$
}

\author{
By David B. Cook ${ }^{2}$ and Ivan H. Sims ${ }^{3}$
}

$\mathrm{T}$

HERE SEEMS to be a widespread and generally accepted conviction among foresters and landowners that American beech (Fagus grandifolia) is a "problem child". Exceptions can be found, locally and in certain industries, where beech is either acceptable or is sought; yet by and large markets for it are poor. Seemingly lumbermen would prefer to leave it in the woods, and foresters would like to get it out of the woods. Why? Are these antipathies of consumer, middleman and grower justified? Can they be overcome? How? These questions gain importance from the widespread occurrence of the species and-in some parts of its range - from its concentration in certain stands of timber.

Beech is one of the most widely distributed of our native hardwoods. It is found from the Martime Provinces of Canada westward to Wisconsin and southward to Texas. It is most prominent in the forests of the Lake States and the northeast. In the beech-birch-maple association it is a key tree, characteristic of the middle slopes above the frosty zones and outside the areas of summer drought. Its commercial importance diminishes toward the southern part of its occurrence along the Applachian Mountains, and it reaches its lowest value, perhaps, near the southern limits of its range.

\section{Silvical Characteristics of Beech}

Its most conspicuous silvical characteristic is its great tolerance of shade and competition at all ages. Seed will germinate and seedlings will develop, even though slowly, in light of very low intensity. This permits it to persist in an understory, and to assume a dominant position when freed from the competition of taller associates. Beech retains for many years its ability to recover from suppression and make rapid growth. Because of its tolerance beech can and often does develop in pure or nearly pure stands of small extent, which tend to stagnate if left unthinned. The shade cast by beech crowns is heavy and its surface roots completely occupy the upper layer of soil, so that only seedlings of extremely tolerant species can establish themselves under it.

Another outstanding characteristic of beech is its susceptibility to injuries. The thin, smooth bark is but poor protection against forest fires and scuffing by skidded logs. The shallow root system likewise has a tender bark easily injured by trampling of livestock, logging, or even foot traffic. Mature or nearly mature trees are not resistant to limb breakage in glaze storms.

1. Paper presented at the annual meeting of the Society of American Foresters, Boston, Massachusetta, December 16 to 18,1948 , and published through the courtesy of the Society of American Foresters.

2. Supervising Forester, N. X. S. Conservation Dept., Albany, N.Y.

3. Chief, Division of Forest Management Research, Northeastern Forest Experiment Station, Upper Darby, Pa. 
Such injuries are followed normally by infection with fungi that attack both sapwod and heartwood. Among the more common of these fungi are species of Daedalea, Schizophyllum, and Polyporus. Sapwood rots are soon followed by heart rot, and this vulnerability to decay and the resulting loss of tree quality and usefulness is a prominent cause of some of the dislike of beech. Recently in Maine an outbreak of beech scale (an insect) and nectria canker associated with it has been developing and spreading westward. There appears to be a distinct possibility that it may become destructive enough to "solve" the "beech problem" over extensive areas by the simple process of killing the beech.

Beech reproduces without much difficulty. Heavy seed crops are borne irregularly, however, and bumper crops only by full-crowned trees. Yet its tolerance is such that advance regeneration can usually be counted upon to develop well ahead of harvest cuttings. Root suckers are likely to develop following injuries to the surface roots or cutting. Almost invariably, however, they become infected with heart rot through the old roots and hence do not qualify as desirable reproduction. Stump sprouts generally originate high on the stump, have mechanically weak attachment, and seldom live long.

Beech mast is highly palatable to wildlife, from bears down to whitefooted deermice, and when available it is readily used. Sprouts and seedlings are browsed by deer and rabbits. Aesthetically its dark green, glossy foliage in summer, and its warm russet autumnal coloring make it a colorful component of the landscape.

At its best beech is a fine tree, 100 feet tall and 3 feet in diameter with a smooth, columnar trunk. Unfortunately, such prime specimens are scarce and are becoming scarcer. Beech is characteristically heavylimbed and, given any considerable amount of sidelight, becomes coarse and limby. Large limbs naturally lead to large and defective knots. Crook and sweep resulting from long years of suppression are all too common.

Silviculturally, therefore, beech (like many other of our species) has its good and bad points. The net result, however, is a species requiring skillful handling but capable of yielding good trees under good management.

\section{GOOD WOOD BUT HARD TO HaNdLE}

Technologically, beech has many good points. In bending strength, hardness, toughness, nail-holding ability and durability it ranks close to or is better than the wood of species associated with it in the forest. It machines about like maple, although not so easily as birch and cherry. It wears well when subject to friction, finishes nicely, and bends readily after steaming. It does not impart taste or odor to foods when used as a container. The sapwood takes preservative treatment well.

On the other side of the ledger, however, the wood has characteristics that make it hard to handle. Heartwood and sapwood have different shrinkage rates. It is not durable in contact with the ground or when exposed to the weather. It shrinks and swells too much to be easily kept 
in place under variable moisture conditions. If slab-sawn lumber is dried too rapidly the longitudinal fibers separate from the medullary rays and surface checking results. The lumber end-checks and splits readily, and when improperly dried it is apt to cup, curl, and twist.

The good qualities of beech wood have by no means been overlooked by wood-using industries. It finds its way into a wide variety of products and uses. Among the more important are destructive distillation, ties, slack cooperage, crate and basket veneer, boxes and crates, furniture (curved and turned parts of chairs, frames for upholstered pieces), handles, brush backs, woodenware, toys, spools, clothes pins, flooring, dairy and poultry equipment, and laundry appliances.

Beech can also be used for pulp in all four of the principal chemical processes: sulfite, sulfate, soda, and semi-chemical. It has been accepted, however, rather than sought for pulpwood. But recent discoveries at the U.S. Forest Products Laboratory at Madison are overcoming earlier difficulties in cooking. The semi-chemical process promises to open up a greatly expanded market for the species as pulpwood.

It is noteworthy that flooring is the nearest approach to construction lumber in the list of uses. All other uses employing sawed material can use relatively short lengths and small pieces. The reason is fairly obvious-beech lumber is difficult to season into straight, flat lumber. Carpenters dislike working with warped lumber. Poor lumber increases construction costs, and customers prefer buildings constructed with straighter, better-looking lumber. But seasoning defects can be planed out of short lengths and narrow boards, even though with considerable waste; so beech finds a market for its good qualities in products requiring small pieces.

\section{The Growth of Prejudice}

The difficulty of manufacturing and delivering good beech lumber long ago started a chain of reactions which has led to the present situation in which neither the tree nor its wood is usually welcome. Poor lumber meant low price and hence low profits to the lumberman; the narrow profit range led to more severe high-grading of beech than of species in better demand; stumpage values also suffered; left-over beeches responded readily to release by expanding crowns and increasing their dominance of the stand; wounds suffered in logging or fires soon led to heavy defectstill further lowering merchantability; and the holdovers, being longlived, hung on while losing value almost yearly. Land occupied by such trees is a liability regardless of the level of forest management practised.

The key to reversing this process of forest deterioration seems to lie in the field of utilization, and very largely in improving the manufacture and seasoning. Under management we feel confident we can grow good beech logs yielding a high percentage of top-grade lumber. But it is futile to do so if the lumber reaches the consumer as No. 3 Common.

For example, the usual portable sawmill is not a suitable place to manufacture beech and possibly never will be. Consider what happens to even a prime $\log$ in such a mill. No equipment being available for the 
re-working of short lengths, the slabs will be heavy. The $4 / 4$ or $8 / 4$ lumber of all grades will be thrown onto a pile along with lumber of other species, where it may lay for a week exposed to sun and wind. Such treatment may not hurt some species, but only a day or two of dry spring wind or summer sun will spoil beech beyond reclaim. Then it goes to the stacks, all too frequently along with other species with different drying requirements. Here the object will be to air-dry the lumber as rapidly as possible so that it can be sold. The usual stack design is too open for beech. Thus drying will be too fast and the lumber will split, warp and face-check. By the time it gets to the processor it is pretty poor material. It is not to be wondered at, then, that such lumber has given beech a bad name. What came off the saw might have been FAS, but by the time it gets to the processor, it is No. 2 Common.

\section{The Seasoning Problem Can be Solved}

But there is no law, natural or man-made, that says beech has to be handled that way. It can be handled differently, and at least a few outfits are treating it right. Let us cite a couple of shining examples.

The Northern Lumber Company of Poland, N.Y., specializes in highgrade northern hardwood lumber. Their log supply runs about 15 per cent beech. In order to produce quality beech lumber they developed a special procedure and kiln schedule. The drying sequence is approximately the same as that commonly used on birch. The novel feature is that they deliver the lumber to the kilns direct from the saw, so that it has no warp or check. The company president has stated that, by this method, they can produce high-grade beech lumber without sacrifice in either thickness or length.

One of the most difficult of tasks is to properly dry thick beech, sections over $6 / 4$ being especially liable to check. Martin E. Fenton, who operates a bolter mill near Jamestown, N.Y., was faced with the problem of utilizing beech from his timberlands. He has developed a system whereby he can produce heavy beech turning squares for the furniture industry. As the squares (up to $14 / 4$ by 52 inches) come from the saw, the ends are dipped in paraffin, then the squares are closely piled in a tight shed with just enough ventilation to prevent molding. The process is slow but rejections on account of grade have been reduced almost to the vanishing point. After final kiln-drying the squares can be used for such exacting items as turned bed legs.

Not long ago the Forest Utilization Service of the Northeastern Forest Experiment Station participated in a study on the use of buffered salt to control the drying rate of $12 / 4$ turning stock. Degrade was greatly reduced and the process appears to have possibilities for general adoption.

The manufacturers of flooring customarily get, whether they want it or not, at least some beech along with their maple and birch. If the proportion of beech is not too high, all goes well. It may go even better in the future, if the campaign started by the National Oak Flooring Manufacturers' Association to encourage use of more beech flooring is successful. 
The Maple Flooring Manufacturers" Association is also "pushing" beech to develop additional outlets.

All these operators are, to some extent, specialists. They fully understand the difficulties of handling beech, do the necessary segregation of products, and exercise the care required to turn out a quality product.

Unfortunately too little beech passes through such mills; too much comes from small, poorly equipped outfits. Because the market is always well supplied with poorly manufactured beech, the processor has come to believe that all beech is that kind. The more skillful producers meet stiff sales resistance for their high-quality product simply because the trade has come to believe that "beech" and "No. 3 Common" always go together.

\section{New Markets, New Methods, New Life}

What can be done about this beech problem that has plagued us so long? There are several possibilities.

First of all, we need more educational campaigns among ultimate consumers-the architect, the home builder, the furniture manufacturer, the plant engineer and the purchasing agent-to teach them that beech lumber can be good and that, for certain uses, the combination of special properties, abundant supply and lower price make it a better wood. Residential and industrial floors, stair treads, small dimension, turning squares and drawer sides are only a few of the uses for which properly manufactured beech is a superior wood. Here we have a straight, honest and at least partially non-competitive product. A number of agencies have indicated a willingness to cooperate.

But there is no point in promoting the sale of a product unless we can deliver it after the demand has been developed. We have relatively few mills that are equipped, and know how, to handle beech. To remedy the situation will take some education and the construction of additional kiln capacity. It may also require some changes in manufacturing procedure, such as the substitution of the bolter and the veneer machine for the conventional head saw.

Lastly, we who grow and cut the timber have a big task to see that such beech logs and bolts as we cut are well prepared, that they meet the consumers' specifications and that the right products are delivered to the right mill. Proper segregation of the several products is one of the keys to more complete and profitable utilization. An off-specification item not only involves a considerable loss, but also a considerable nuisance around any plant. Also, it costs money just to throw it away. For example, no matter how fine the outer portions, the veneer plant will have trouble with a hollow log. The average sawmill is equipped to handle logs 8 feet and longer; the bolter mill requirements are 6 feet or shorter. Rough and knotty material might better go into pulpwood. While we are building better markets for beech, we may have to take special pains to see that the primary industries get logs in the form most useful to them. 
Whatever new and unorthodox bulk markets can be found for beech would be helpful in ridding the woods of poor trees now present. But. that problem is not peculiar to beech, and perhaps is even less acute for it than for a number of other species that lack the silvicultural and technical qualities of beech. On the better sites and where the best possible management should be practised the forest manager can employ known methods of getting rid of truly worthless trees, as by girdling or poisoning. In situations now justifying only a lower level of management we may have to wait for the bulk market to develop before we can begin to solve the beech problem. Pending that time, the forest manager and silviculturist would doubtless be satisfied if beech could participate in present markets to the extent to which it is entitled. 